\title{
Numerical modelling of heat dissipation for the Pin-On-Disc type tribometer
}

\author{
Marian Bartoszuk(1), Bougoffa Mohammed Seyf Eddine(2) \\ (1) Department of Manufacturing Engineering and Automation, Opole University of Technology, Opole, POLAND \\ e-mail:m.bartoszuk@po.edu.pl \\ (2) Laboratoire de Science et Génie des Matériaux, Faculté de Génie Mécanique et Procédés U.S.T.H.B, B.P. 32 El Alia, Bab \\ Ezzouar, Alger 16111, ALGIERIA \\ e-mail: Seif.bougoffa@gmail.com
}

\section{SUMMARY}

This article presents numerical tests of heat distribution for the Pin-On-Disc type frictional contact. The tests were conducted for the friction pair brass CuZn39Pb2 (pin) - cast iron GJL250 (disc). The heat distribution was tested both experimentally and numerically. Experimental tests were carried out on a conventional CA 6140 lathe properly adapted for these tests. The simulations used the method of elementary balances (MEB) based on an explicit calculation algorithm. The studies were carried out with a normal force of $5 \mathrm{~N}$ and three cutting speeds of $0.24,0.35$, and $0.48 \mathrm{~m} / \mathrm{s}$ respectively. The measurements were made after the process had lasted $0,5,10,15,20,25$, and 30 minutes. As a result of the research, the average and maximum temperature of the measurement point located directly behind the pin-disc contact field was determined. On the basis of the conducted analyses, the imperfection of the applied calculation method was indicated as the probable cause of discrepancies in experimental and simulation results and the acceptance for calculations of constant and time-varying thermo-physical properties of friction pair materials. In addition, the studies proved that a change in the calculation time step has little effect on the average and maximum temperature of the measurement point.

KEY WORDS: Pin-On-Disc type friction; numerical simulations; method of elementary balances.

\section{NOMENCLATURE:}

$v$ - friction velocity $[\mathrm{m} / \mathrm{s}]$,

$F$ - clamping force $[N]$,

$t$ - friction time $[\mathrm{min}]$,

$T_{o}$ - temperature inside the calculation cell $\left[{ }^{\circ} \mathrm{C}\right]$,

$T_{G}$ - temperature in the cell above the calculation cell $\left[{ }^{\circ} \mathrm{C}\right]$,

$T_{P}$ - temperature on the right-hand side of the calculation cell $\left[{ }^{\circ} \mathrm{C}\right]$, 
$T_{L}$ - temperature on the left side of the calculation cell $\left[{ }^{\circ} \mathrm{C}\right]$,

$T_{D}$ - temperature in the cell below the calculation cell $\left[{ }^{\circ} \mathrm{C}\right]$,

$T_{p \nmid}$ - temperature on the right-hand side of the calculation cell $\left[{ }^{\circ} \mathrm{C}\right]$,

Fo - Fourier number,

$B i-$ Biot number,

$\dot{q}_{v}$ - frictional heat flux density $\left[\mathrm{W} / \mathrm{m}^{2}\right]$,

$\alpha$ - thermal diffusivity coefficient $\left[\mathrm{m}^{2} / \mathrm{s}\right]$,

$\lambda$ - thermal conductivity coefficient $[W /(m K)]$,

$\Delta t$ - time step $[s]$ adopted for calculation,

$\Delta x$ - mesh size of the calculation grid [m].

\section{INTRODUCTION}

Basically, it can be said that numerical modelling is used to gain a better understanding of phenomena for which experimental studies are difficult or cost-intensive. The example here is the numerical modelling of heat dissipation during cutting $[1,2,3,4,5]$. In order to gain a better understanding of the processes at the interface between the cutting insert and the chip, such testing is often supported by experiments on various types of tribometers. The purpose of these tests is to determine the nature of the interaction of frictional contact between the cutting tool material and the workpiece material. Tribometers are used to reproduce the conditions of the chip-tool interface [6,7]. Although it is an idealised contact, such testing allows for a detailed analysis of different process characteristics. Apart from friction, the wear of interacting surfaces $[8,9]$ and the generation and dissipation of temperature in the contact zone $[10,11]$ are tested on the tribometer. The use of numerical methods allows for an extended analysis of friction or any chosen phenomenon accompanying friction. It allows to analyse the modelled quantity in any cross-section of the computational model or to observe phenomena at any time during the process $[9,11]$.

For the modelling of tribological phenomena, highly specialized FEM software packages such as ABAQUS or ANSYS are usually used $[10,11,12]$. Due to their complexity and calculation possibilities, such packages are very expensive. For example, Singh et al. [10], in their studies, analysed the changes in the contact temperature distribution caused by an increase in the mechanical load of the contact. They used the ANSYS software in the simulations. Abdullah and Schlattmann also used ANSYS to simulate friction [11]. They have proven the effect of heat accumulation right at the pin-disk contact surface. They pointed out that the scale of this effect depends on the thermal conductivity value of friction materials. They showed that the accumulation of temperature decreases with the increase of the friction pair heat conduction coefficients. In contrast, Curreli and others [12] have proven in their studies that applying a global and local approach to simulating tribological phenomena can significantly reduce the simulation duration. It proved that this procedure is particularly suitable for examining certain tribological aspects which have always been considered too time-consuming and costly. There are only a few examples of papers in this article from the thematic scope. However, a wider literature review has shown a lack of papers focusing on the phenomena of temperature generation and distribution in the initial moments of friction. As you know, it is during this period that the most dynamic increase in temperature occurs, and any errors at this stage will affect the final result. For this reason, the authors attempted to build a simulation algorithm to 
describe the phenomena of distribution and accumulation of heat in the elements of friction pair during the first few rotations of the disc.

\section{TEST METHODOLOGY}

For the tests, the following materials were used as the pin/disc friction pair:

- pin - brass CuZn39Pb2,

- disc - cast iron EN-GJL-250.

The following process parameters were adopted in the tests:

- friction velocity $v=0.24,0.35$ and $0.48[\mathrm{~m} / \mathrm{s}]$,

- clamping force $F=5[N]$,

- friction time $t=0,5,10,15,20,25$ and 30 [minutes].

The friction pair materials and friction process parameters were chosen not by accident. Their values result directly from previous research [13], and suggestions on the part of the industry.

The testing was carried out in two stages. The first stage of the work included carrying out experimental tests on the friction process, where the friction temperature information was collected and the effects of pin and disc wear were observed after the tests. In the second stage, computer simulations of heat dissipation in the contact field were performed.

\subsection{EXPERIMENT}

The experimental tests of the friction process were carried out on a tribometer built on the basis of a conventional CA 6140 lathe, equipped with a suitable disc placed in the lathe chuck and a pin fixed in the tool holder. The clamping force of the pin on the disc was regulated mechanically by a spring. The accuracy of the adjustment of the clamping force was $\pm 1 N$. The diagram of the test bench and its basic dimensions are shown in Figure 1. The focus of the tests was to measure the temperature of the disc immediately after passing through the friction zone. These measurements were made with the use of an IR pyrometer from UNI-T, UT 301C. This pyrometer provided a measuring field with a diameter of $2 \mathrm{~mm}$. The position of the pyrometer in the measuring system and the location of the measurement point on the disc are shown in Figure 2. Temperature measurements were carried out with an accuracy of $\pm 0.1^{\circ} \mathrm{C}$.

a)

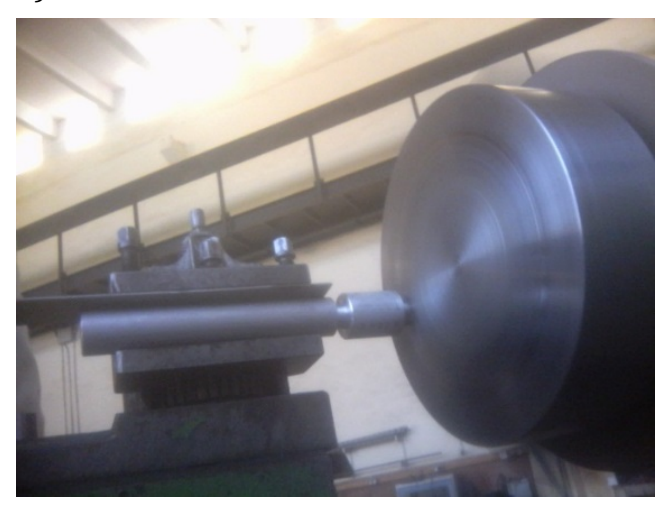

b)

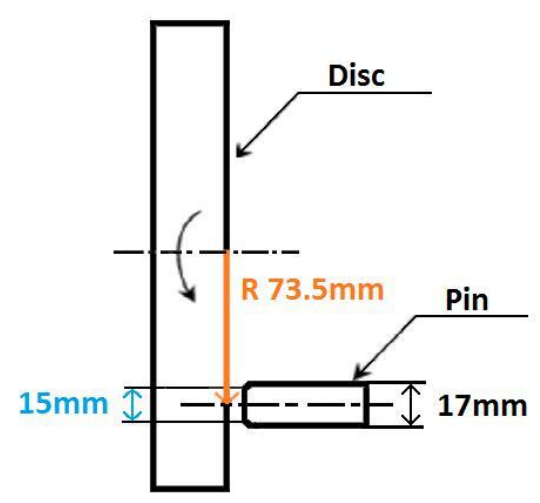

Fig. 1 Test bench, a) pin-disk contact view, b) basic dimensions 


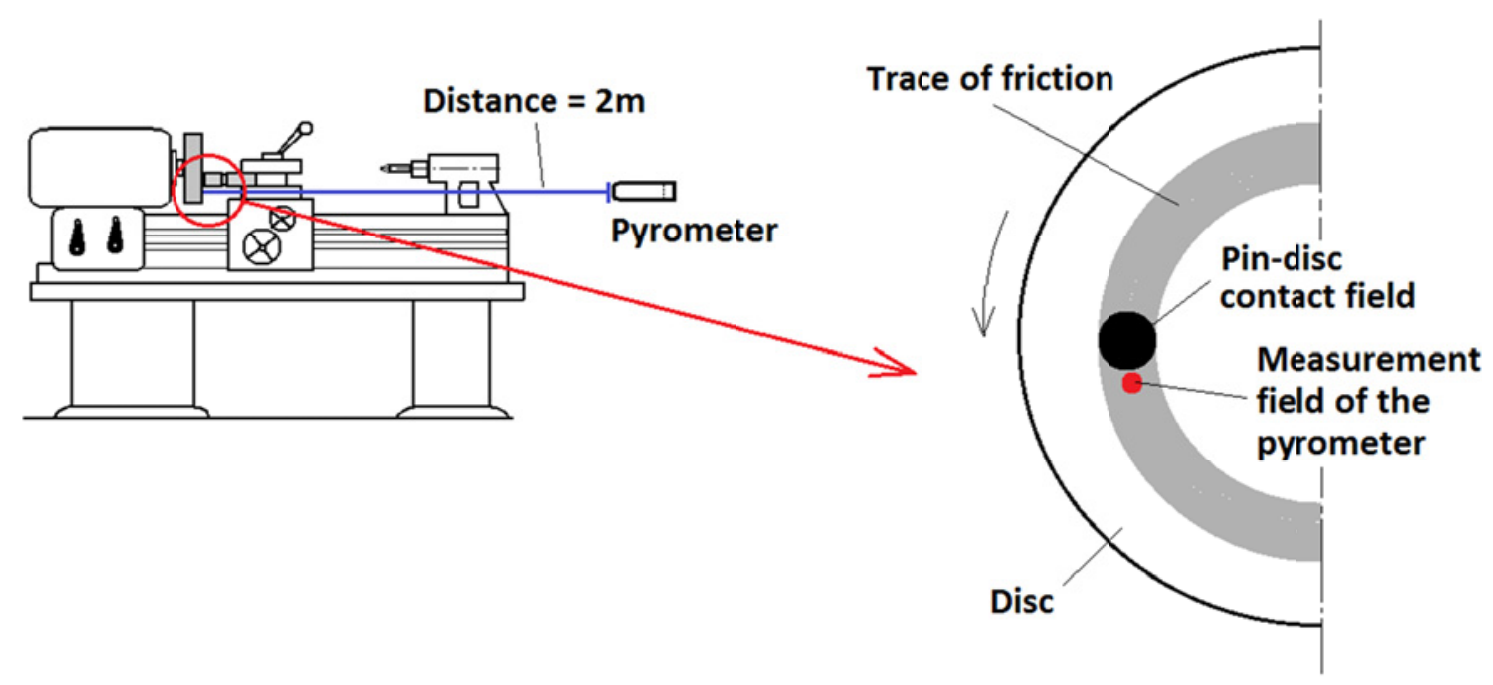

Fig. 2 Diagram of the test bench

\subsection{NUMERIC MODELLING}

In order to better understand the phenomenon of heat dissipation in the pin-disk contact zone, numerical simulations were conducted using a special variety of the FDM method called the method of elementary balances (MEB). This method uses only Fourier's law and a typical computational grid. Therefore, it comprises differential equations defined on the basis of energy balances for all discrete elements of the calculation model. The simplicity of this method enables calculations to be carried out in any spreadsheet. In the presented studies Microsoft Excel was used for calculations. In the calculation, a grid with square elements with a mesh size of $0.25 \mathrm{~mm}$ was used. When building the calculation model, it was assumed that each cell of the spreadsheet is assigned one discrete element of the analytical model. As a result, the model was built as a set of cells containing the relevant formulas and values. In this way, both geometric and physical features of the modelled process were reproduced. The general appearance of the calculation model is shown in Figure 3.

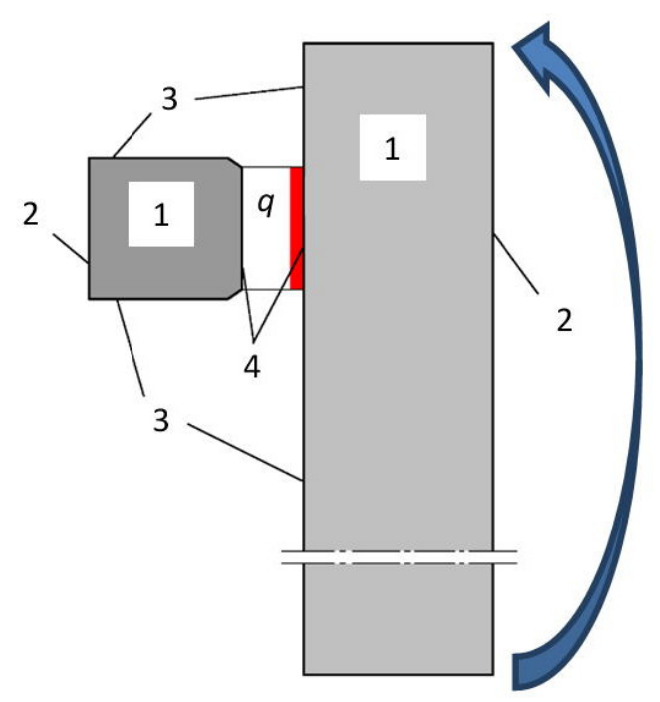

Fig. 3 Calculation model 
In the figure, the relevant calculation formulas entered in the sheet are marked with numbers. Their general notation is shown below:

1. Internal formula:

$$
T_{0}^{+1}=T_{0}(1-4 \Delta F o)+\Delta F o\left(T_{G}+T_{P}+T_{G}+T_{L}+\frac{\dot{q}_{v}(\Delta x)^{2}}{\lambda}\right)
$$

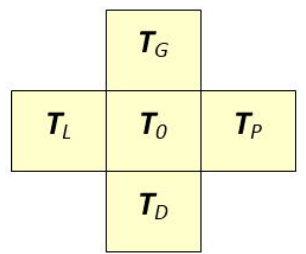

2. Formula on the edge in contact with the rest of the material (Neumann condition):

$$
T_{0}^{+1}=T_{0}(1-3 \Delta F o)+\Delta F o\left(T_{G}+T_{P}+T_{D}+\frac{\dot{q}_{L}}{\lambda} \Delta x+\frac{\dot{q}_{v}(\Delta x)^{2}}{\lambda}\right)
$$

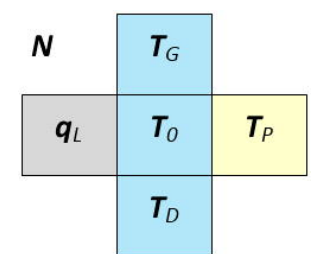

3. Formula on the edge in contact with the surrounding atmosphere (Fourier's condition):

$$
T_{0}^{+1}=T_{0}\left[1-F o\left(3+\Delta B i^{D}\right)\right]+\Delta F o\left(\Delta B i^{D} T_{p ł}^{D}+T_{P}+T_{G}+T_{L}+\frac{\dot{q}_{v}(\Delta x)^{2}}{\lambda}\right)
$$

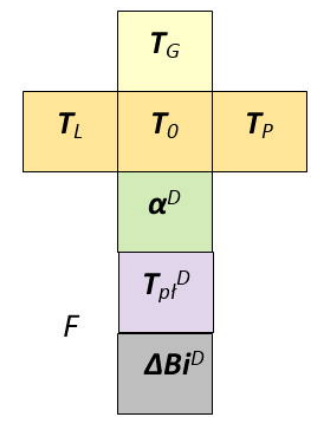

4. Formula on the edge which is the contact between the pin and disc material (condition of the IV type):

$$
T_{0}^{+1}=T_{0}^{A}\left(1-\Delta F o_{A}\left(3+K \lambda_{B}\right)\right)+\Delta F o_{A}\left(T_{G}^{A}+T_{P}^{B} K \lambda_{B}+T_{D}^{A}+T_{L}^{A}+\frac{\dot{q}_{v}(\Delta x)^{2}}{\lambda}\right)
$$

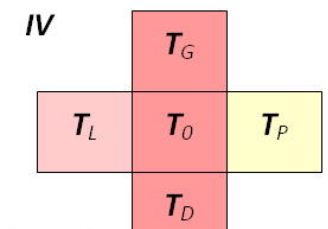

Mat. A

Mat. B

In addition to the formulas mentioned above, their combination is also used in the calculations. Corner formulas can be given here as an example: 
Corner formula which is a combination of Fourier's formula and Neumann's formula:

$$
T_{0}^{+1}=T_{0}\left(1-\Delta F o\left(2+\Delta B i^{D}\right)\right)+\Delta F o\left(T_{G}+\frac{\dot{q}_{P} \Delta x}{\lambda}+\Delta B i^{D} T_{p \nmid}^{D}+T_{L}+\frac{\dot{q}_{v}(\Delta x)^{2}}{\lambda}\right)
$$

Corner formula which is a combination of Fourier formula and Type IV condition:

$$
T_{0}^{+1}=T_{0}^{A}\left(1-\Delta F o_{A}\left(2+\Delta B i^{G}+K \lambda_{B}\right)\right)+\Delta F o_{A}\left(\Delta B i^{G} T_{p \nmid}^{G}+K \lambda_{B} T_{P}^{B}+T_{D}^{A}+T_{L}^{A}+\frac{\dot{q}_{v}(\Delta x)^{2}}{\lambda}\right)
$$

The model shown in Figure 3 shows a two-dimensional temperature field obtained for the plane which is the expansion of the disc track pitch diameter and pin section. As a result of such calculations, the temperature fields for the pin and disc were obtained, as well as temperature values in node points of the calculation grid for time $t$ being a multiple of time leap $\Delta t$ accepted for calculations. The calculations were performed with a step of 1000 iterations. Therefore, the moments of time in which the results of the calculations can be observed are respectively: $0.0,0.347,0.694,1.041$, etc.

In addition to its undoubted advantages in terms of simplicity and low hardware requirements, the explicit calculation algorithm used in these studies has two major drawbacks. These include problems in obtaining the stability of calculations forcing the use of a small step of calculation time $\Delta t$, and the resulting long calculation time causing numerical integration errors that grow with calculation time.

\section{ANALYSIS OF TEST RESULTS}

The experimental tests of the friction process were conducted for different friction velocities. Regardless of the velocity, temperature measurements were taken for the same time intervals of $0,5,10,15,25$, and 30 minutes, respectively. As a result, the number of rotations made by the disc was different. Table 1 shows the values of temperature increase due to friction recorded for all the examined cases.

\begin{tabular}{|c|c|c|c|c|c|c|}
\hline \multirow{2}{*}{$\begin{array}{l}\text { Time } \\
\text { [min] }\end{array}$} & \multicolumn{2}{|c|}{$v=0.24[\mathrm{~m} / \mathrm{s}]$} & \multicolumn{2}{|c|}{$v=0.35[\mathrm{~m} / \mathrm{s}]$} & \multicolumn{2}{|c|}{$v=0.48[\mathrm{~m} / \mathrm{s}]$} \\
\hline & Cycles & $\Delta T_{m}\left[{ }^{\circ} \mathrm{C}\right]$ & Cycles & $\Delta T_{m}\left[{ }^{\circ} \mathrm{C}\right]$ & Cycles & $\Delta T_{m}\left[{ }^{\circ} \mathrm{C}\right]$ \\
\hline 0 & 0 & 11.9 & 0 & 12.1 & 0 & 12.7 \\
\hline 5 & 72 & 12.1 & 105 & 12.5 & 144 & 13.1 \\
\hline 10 & 144 & 12.5 & 210 & 12.7 & 288 & 13.8 \\
\hline 15 & 216 & 12.6 & 315 & 12.9 & 432 & 13.9 \\
\hline 20 & 288 & 12.5 & 420 & 13.0 & 576 & 13.8 \\
\hline 25 & 360 & 12.6 & 525 & 13.1 & 720 & 13.8 \\
\hline 30 & 432 & 12.6 & 630 & 13.0 & 864 & 13.8 \\
\hline
\end{tabular}

Table 1 Summary of experimental results 
For the experimental results obtained in this way, numerical simulations of heat dissipation at the pin-disc interface were conducted. Constant thermo-physical properties of the materials tested shown in Table 2 were assumed for calculations. The calculations were carried out for a friction time of 1 second, as this is how long the first real measurement took during the experiment. The comparison of the results obtained experimentally with the simulation results for time $t=0 \mathrm{~min}$ is shown in Figure 4. This comparison shows that the average measurement point temperature shows a noticeable increase in deviation as the cutting speed increases. A difference of $-19.3 \%$ was noted for the cutting speed of $0.24 \mathrm{~m} / \mathrm{s}$. For 0.35 , the difference was $+4.9 \%$, whereas for the velocity $0.48,+20.4 \%$. A comparison of the numerical values of the results shown in Figure 4 is presented in Table 3.

Table 2 Thermo-physical properties of tested materials adopted for calculations [14, 15]

\begin{tabular}{cccc}
\hline Material & $\begin{array}{c}\text { Density } \\
\rho\left[\mathrm{kg} / \mathrm{m}^{3}\right]\end{array}$ & $\begin{array}{c}\text { Thermal conductivity } \\
{\left[W / \mathrm{kg}{ }^{\circ} \mathrm{C}\right]}\end{array}$ & $\begin{array}{c}\text { Heat capacity } \\
\mathrm{c}_{p}\left[\mathrm{~J} / \mathrm{kg}{ }^{\circ} \mathrm{C}\right]\end{array}$ \\
\hline \hline CuZn39Pb2 & 8.440 & 109 & 377 \\
\hline EN-GJL-250 & 7.100 & 48.8 & 460 \\
\hline
\end{tabular}

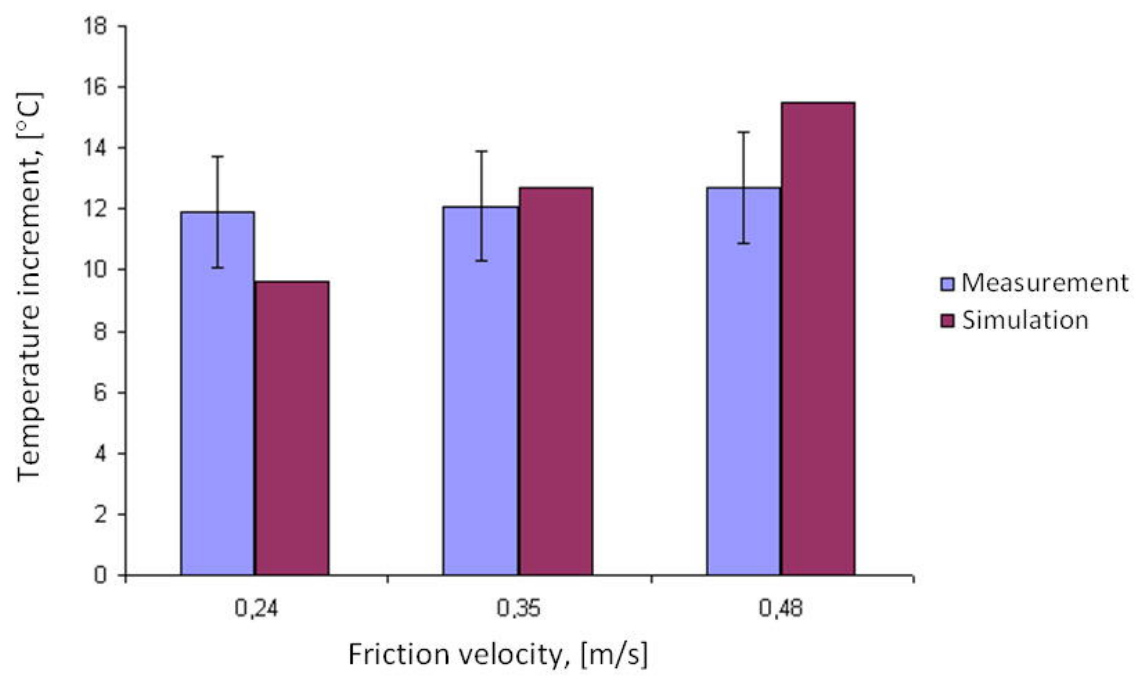

Fig. 4 Graphical comparison of experiment and simulation results for the time of 0 min

This arrangement of the simulation result deviation from the experiment result shows that the dynamics of the increase of the friction temperature recorded with the increase of the cutting speed for the simulation is noticeably higher than for the experiment. Many years of experience in implementing various numerical calculations suggest that this phenomenon is probably due to the simulation model imperfections, in particular the adoption of values of thermo-physical parameters of friction pair materials for constant calculations $[2,4,5]$. It is known that the time-varying and temperature-dependent thermal conductivity of the friction pair, especially when the value of conductivity increases with the temperature, causes a decrease in the maximum and average contact temperature [4].

In computer simulations, a discrepancy of $\pm 20 \%$ between the results of simulations and experiments is often considered fine. This is due to the fact that a lot of factors can disturb 
the calculation results. Therefore, numerical calculations are treated as an approximate result $[4,5]$.

Table 3 Summary of results obtained experimentally with the results of computer simulations for the time of 0 min

\begin{tabular}{ccccc}
\hline $\begin{array}{c}\text { Frictional } \\
\text { velocity } \\
v,[\mathrm{~m} / \mathrm{s}]\end{array}$ & $\begin{array}{c}\text { Average temperature rise of the } \\
\left.\text { measurement point } T_{m},{ }^{\circ} \mathrm{C}\right]\end{array}$ & $\begin{array}{c}\text { Deviation } \\
\text { measurement }\end{array}$ & simulation & $\begin{array}{c}\text { Maximum temperature of } \\
\text { frictional contact }\end{array}$ \\
\hline \hline 0.24 & 11.9 & 9.6 & -19.3 & $T_{\max ,}\left[{ }^{\circ} \mathrm{C}\right]$ \\
\hline 0.35 & 12.1 & 12.7 & 4.9 & 32.4 \\
\hline 0.48 & 12.7 & 15.3 & 20.4 & 36.3 \\
\hline
\end{tabular}

The table additionally demonstrates the maximum temperature value generated at the pindisc contact. The comparative analysis of the results indicates that the value of the maximum temperature of the pin-disc contact is subject to similar changes as the average measurement point temperature. Moreover, these changes are proportional to the frictional velocity. Therefore, it can be suspected that the deviations are caused by too much friction heat being introduced into the model. The low value of the average measurement point temperature at a velocity of $0.24 \mathrm{~m} / \mathrm{s}$ is a favourable phenomenon, as the calculation model is still stabilising during this time. Therefore, the temperature will increase slightly with the calculation time. This is clearly visible in Figure 5. The process of temperature rise and stabilisation for higher friction velocities is similar. However, due to a different step in the time frame used for calculations, stabilisation is achieved after a shorter period of friction.

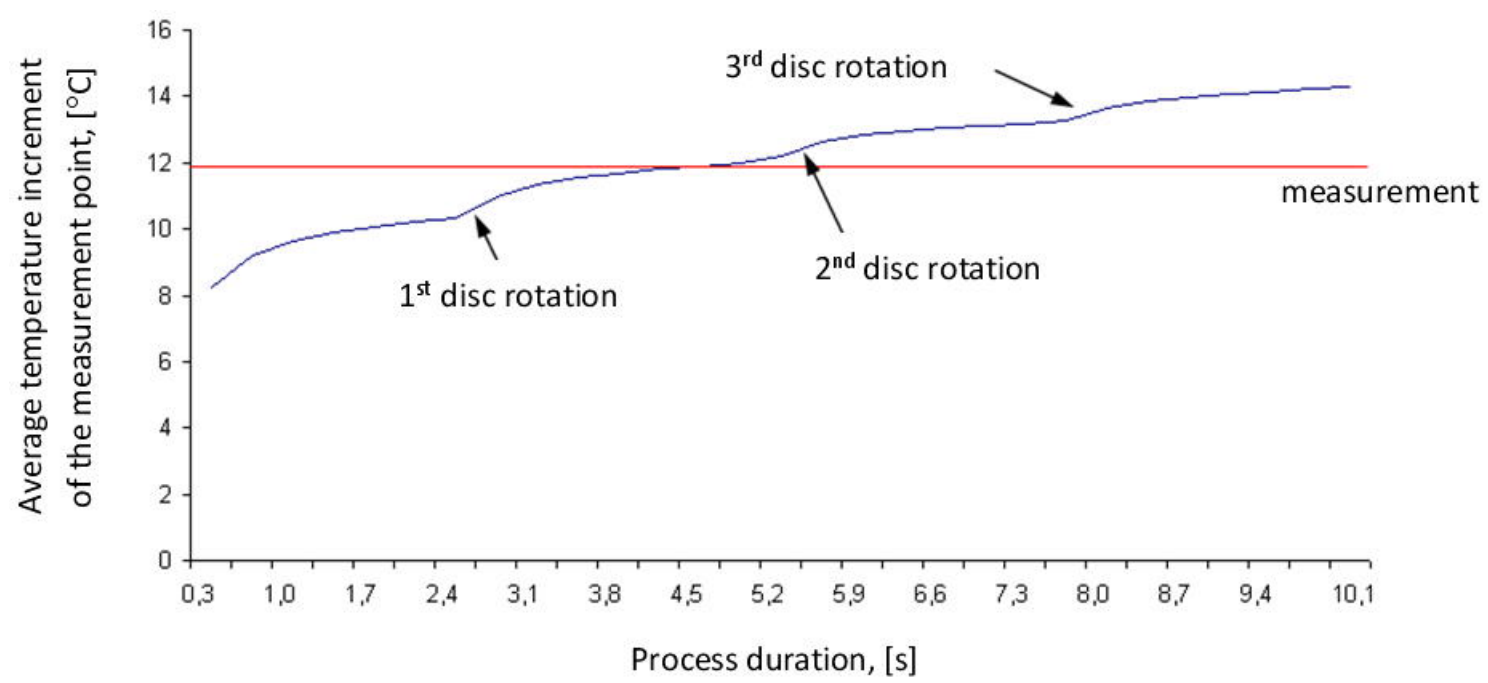

Fig. 5 Change of the average temperature increment of the measurement point as a function of the process duration

The step changes in the curve are caused by the disc making a full rotation. Then the temperature accumulated in the disc is added to the currently generated temperature. This 
phenomenon can also be observed by analysing the temperature dissipation on temperature distribution maps. A shape example of the front face of the temperature wave accumulated in the disc is shown in Figure 6.

In the figure, the direction of movement made with the calculation grid of the disc crosssection is marked in green. The red colour shows the directions of propagation of the front face of the temperature wave. The analysis of the shown data suggests that an increase in the friction velocity results in a too intensive increase in the amount of friction heat entering the calculation model through the pin-disc contact. It is suspected that this phenomenon may be due to errors in the construction of the simulation model or its properties. The reason for such an error may be the use of identical construction in all the calculation models. In the calculation models, only the intensity of the heat source, the step of time with which the calculation was carried out, and the time of the heat flux impact on the pin-disk contact resulting from the friction velocity were changed. Analysis of the calculation Formulas notation (1-6) indicates that the intensity of the heat source and the rate of temperature propagation can be influenced by changing the Fourier number value. Knowing that the discrete Fourier number can be expressed by the Formula (7), its value can be influenced by changing the time step $\Delta t$ with which the calculations are performed:

$$
\Delta F o=\frac{\alpha \Delta t}{(\Delta x)^{2}}
$$

where: $\alpha$ - thermal diffusivity coefficient $\left[\mathrm{m}^{2} / \mathrm{s}\right]$,

$\Delta t$ - time step $[s]$ adopted for calculation,

$\Delta x$ - mesh size of the calculation grid $[m]$.
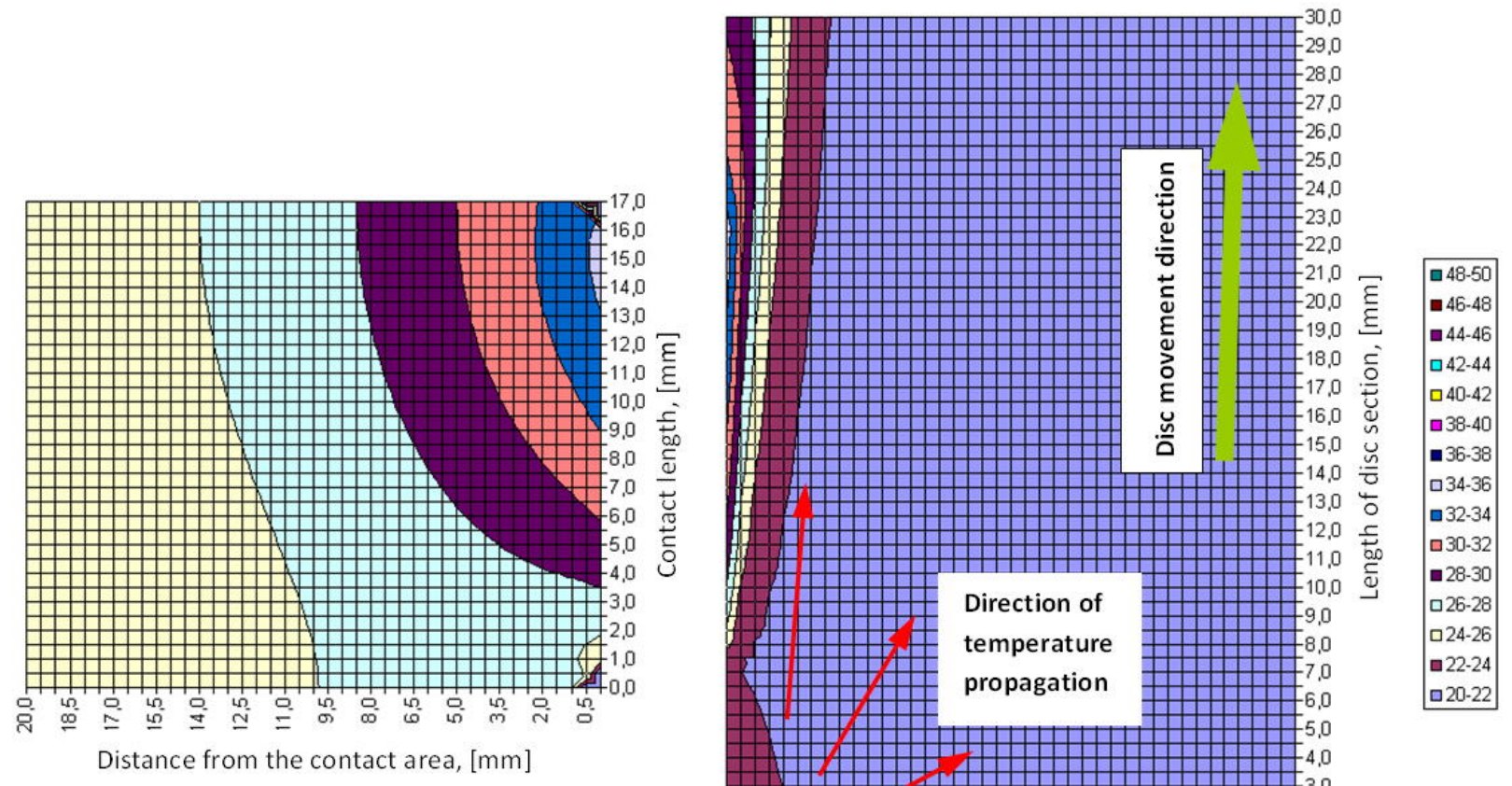

Fig. 6 Temperature fields obtained for a friction velocity of $0.24 \mathrm{~m} / \mathrm{s}$ and a simulation time of 5.208s 
The example values of the Fourier number used in the calculation are respectively:

- $F o=0.195751$ for force $F=0.5[N]$ and friction velocity $v=0.35[\mathrm{~m} / \mathrm{s}]$,

- $F o=0.160314$ for force $F=0.5[N]$ and friction velocity $v=0.24[\mathrm{~m} / \mathrm{s}]$,

- $F o=0.142735$ for force $F=0.5[N]$ and friction velocity $v=0.48[\mathrm{~m} / \mathrm{s}]$.

These studies examined with what intensity the calculation result is affected by the change of time step $\Delta t$. For this purpose, simulations were carried out in which the time step adopted for the calculation was reduced in steps of $-10 \%$ to $-50 \%$. The results obtained are shown in Table 4. Contrary to expectations, the effect of the calculation time step change on the average measurement point temperature is moderate. A decrease in the time step $\Delta t$ by $10 \%$ results in a reduction of the value of the deviation by about $5 \%$. The maximum contact temperature changes even less. The testing noted a decrease in its value by about $2.5 \%$. Therefore, the calculation time step is not a decisive factor for the accuracy of numerical calculations. By skilfully selecting its value, one can only correct the result deviation to a small extent.

Table 4 Influence of time step $\Delta t$ on the average temperature value of the measurement point

\begin{tabular}{|c|c|c|c|c|c|}
\hline $\begin{array}{l}\text { Time } \\
\text { step }\end{array}$ & $\begin{array}{c}\text { Average temperature } \\
\text { increase of the } \\
\text { measurement point }\end{array}$ & Deviation & $\begin{array}{c}\text { Maximum } \\
\text { temperature of } \\
\text { frictional contact }\end{array}$ & $\begin{array}{l}\text { Number of } \\
\text { iterations }\end{array}$ & $\begin{array}{l}\text { Duration of the } \\
\text { friction process }\end{array}$ \\
\hline$\Delta t[s]$ & $\Delta T_{m}\left[{ }^{\circ} \mathrm{C}\right]$ & $\%$ & $T_{\max },\left[{ }^{\circ} \mathrm{C}\right]$ & & {$[s]$} \\
\hline $2.604 E-04$ & 15.5 & 20.4 & 39.4 & 4000 & 1.042 \\
\hline$-10 \%$ & 14.7 & 15.7 & 38.3 & 4000 & 0.938 \\
\hline$-20 \%$ & 14.1 & 11.1 & 37.5 & 5000 & 1.042 \\
\hline$-30 \%$ & 14.0 & 11.0 & 37.1 & 6000 & 1.094 \\
\hline$-40 \%$ & 13.6 & 7.0 & 36.2 & 7000 & 1.094 \\
\hline$-50 \%$ & 12.5 & -1.6 & 34.9 & 8000 & 1.042 \\
\hline
\end{tabular}

From experience, another factor that may affect the accuracy of the simulation is the choice of thermo-physical properties of both materials. The calculation accuracy could improve the acceptance of temperature-dependent thermo-physical properties for calculation. In this calculation, due to the lack of such data, fixed properties were used for calculation (Table 2).

\section{CONCLUSIONS}

The analyses of thermal characteristics of the pin-on-disc contact presented in the paper indicate that the values of the average measurement point temperature obtained by means of the numerical method have acceptable compliance with the measurements. The recorded differences in results vary from $-19.3 \%$ (for friction velocity $v=0.24 \mathrm{~m} / \mathrm{s}$ ) to $+20.4 \%$ (for $v=0.48$ $\mathrm{m} / \mathrm{s}$ ). The results of numerical calculations indicate a clear tendency to increase the deviation of the result as the friction velocity increases, which is due to the noticeably higher dynamics of the increase of the friction temperature with the increase of the cutting speed recorded for the simulation. It can be assumed that this trend is due to simulation model imperfections and, 
in particular, the adoption of values for the thermo-physical parameters of friction pair materials for the calculation of constants. In addition, the studies tested the possibility of correcting the final simulation result by changing the calculation time step $\Delta t$. The research has shown that the time step $\Delta t$ has a limited impact on the average measurement point temperature. Decreasing the step $\Delta t$ by $10 \%$ results in the average contact temperature decrease by about $5 \%$ and the maximum temperature by about $2.5 \%$. As a result, reducing the time step $\Delta t$ by $50 \%$ caused the average temperature of the pin-disc contact to change from 15.5 to $12.5^{\circ} \mathrm{C}$. At the same time, the maximum contact temperature decreased from 39.4 to $43.9^{\circ} \mathrm{C}$.

In summary, it can be concluded that the continuation of these studies should focus on verifying the effect on the accuracy of simulation calculations of the thermo-physical properties of friction pair materials described as a function of temperature. In addition, the suitability for estimating the average and maximum temperature of the pin-disc contact of the implicit calculation algorithm, considered by many researchers to be more accurate, should be checked.

\section{REFERENCES}

[1] M. Blasiak, $Ł$ Nowakowaki, Simulation research of the temperature distribution during face milling, EPJ Web of Conferences (EFM 2018), Vol. 213, pp. 1-4, 2019.

https://doi.org/10.1051/epjconf/201921302004

[2] W. Grzesik, P. Niesłony, M. Bartoszuk, Modelling of the cutting process analytical and simulation methods, Advances in Manufacturing Science and Technology, Vol. 33, No. 1, pp. 5-29, 2009.

[3] D. Petković, M. Madić, M. Radovanović, P. Janković, G. Radenković, Modeling of cutting temperature in the biomedical stainless steel turning process, Thermal Science, Vol. 20, No. 5, pp. 1345-1354, 2016. https://doi.org/10.2298/TSCI16S5345P

[4] M. Bartoszuk, W. Grzesik, Numerical prediction of the interface temperature using updated Finie Difference Approach, Advanced Materials Research, Vol. 223, pp. 231-239, 2011. https://doi.org/10.4028/www.scientific.net/AMR.223.231

[5] W. Grzesik, M. Bartoszuk, P. Niesłony, Finie Difference Analysis of the Thermal Bahaviour of Coated Tools in Orthogonal Cutting of Steels, J. Mach. Tools Manuf., Vol. 44, No. 14, pp. 1451-1462, 2004. https://doi.org/10.1016/j.ijmachtools.2004.05.008

[6] J. Hájek, A. Kř́ž, Tribology in cutting process and comparison between" PIN-on-DISC" andcutting test, AITC-AIT 2006 International Conference on Tribology, 20-22 September Parma, Italy, 2006.

[7] V.A.M. Cristino, P.A.R. Rosa, P. A. F. On the utilization of pin-on-disc simulative tests for the calibration of friction in metal cutting. Proceedings of the Institution of Mechanical Engineers Part J Journal of Engineering Tribology, Vol. 224, No. 2, pp. 169-177, 2010.

https://doi.org/10.1243/13506501JET639

[8] J. Salguero, J. M. Vazquez-Martinez, I. Del Sol, Application of Pin-On-Disc Techniques for the Study of Tribological Interferences in the Dry Machining of A92024-T3 (Al-Cu) Alloys, Materials MDPI, Vol. 11, No. 7, pp. 1236, 2018.

https://doi.org/10.3390/ma11071236 
[9] V. Hegadekatte, N. Huber, O. Kraft, Modeling and Simulation of Wear in a Pin on Disc Tribometer, Tribology Letters, Vol. 24, No. 1, pp. 51-60, 2006.

https://doi.org/10.1007/s11249-006-9144-2

[10] A.K. Singh, V. Ranjan, R. Tyagi, B.N. Singh, Numerical analysis of temperature distribution in sliding contacts of pin on disc model, Vibroengineering Procedia, Vol. 29, pp. 274-278, 2019. https://doi.org/10.21595/vp.2019.21139

[11] O.I. Abdullah, J. Schlattmann, Temperature analysis of a pin-on-disc tribology test using experimental and numerical approaches, Friction, Vol. 4, No. 2, pp. 135-143, 2016.

https://doi.org/10.1007/s40544-016-0110-1

[12] C. Curreli, L. Mattei, F. Di Puccio, Finite element simulations of pin-on-disc wear tests using submodeling, XXIII Conference, The Italian Association of Theoretical and Applied Mechanics, 4-7 September, Salerno, Italy, pp. 587-593, 2017.

[13] B.M. Seyf Eddine, M. Noura, A Comparative Study on the Tribological Behavior of SAEAISI 1055 Steel and Brass (CuZn39Pb2) a Pin on Disc Type of Contact, Defect and Diffusion Form, Vol. 397, pp. 147-160, 2019.

https://doi.org/10.4028/www.scientific.net/DDF.397.147

[14] L.A. Dobrzański, W. Sitek, J. Trzeska, K. Gołombek, E. Hajduczek, Zasady doboru materiałów inżynierskich z kartami charakterystyk, Wydawnictwo Politechniki Śląskiej, Gliwice 2000.

[15] Website of a supplier of construction materials: https://www.dostal.com.pl/metalekolorowe-mosiadz.html Accessed 16.07.2020.

[16] M. Krzeszowiec, J. Małachowski, Badanie wpływu sformułowania elementu skończonego oraz schematu rozwiązywania równania ruchu na wyniki analizy MES na przykładzie niesymetrycznie obciążonej płyty, Biuletyn WAT, Vol. 64, No. 1, pp. 139-159, 2015.

https://doi.org/10.5604/12345865.1145498 